\title{
DETERMINAÇÕES MODAIS DA EFETIVIDADE NA LÓGICA DA ESSÊNCIA HEGELIANA
}

\author{
Agemir Bavaresco \\ Christian Iber \\ PUC - RS
}

\begin{abstract}
Resumo: A teoria da modalidade hegeliana é tematizada no segundo capítulo da terceira seção da Lógica da Essência. Hegel explicita, aqui, a efetividade que se determina nas chamadas modalidades: contingência, possibilidade e necessidade. As modalidades explicitam a efetividade na determinação formal, real e absoluta. A lógica das modalidades, assim como toda a lógica objetiva, tem uma função crítica. Ela é a apresentação crítica da determinação lógico-modal da efetividade que é feita, habitualmente, pelo entendimento. Os modos de determinação apresentados, criticamente, da efetividade têm tanto um status ontológico como também um status epistemológico. Duas leituras são, então, possíveis: ontológica e epistemológica que se complementam reciprocamente.
\end{abstract}

Palavras-Chaves: Lógica das modalidades; contingência; possibilidade; necessidade.

\begin{abstract}
The theory of Hegelian modality is the matized in the second chapter of the third section of the Logic of Essence. Hegel explains here the effectiveness that determines the so-called modalities: contingency, possibility and necessity. The modalities explicit the effectiveness in formal determination, real and absolute. The logic of modalities, as well as any objective logic, plays a critical role. It is the critical presentation of logical-modal determination of effectiveness that is made usually by understanding. Modes of determination presented critically of the effectiveness have both an ontological status as well as an epistemological status. Two readings are then possible: ontological and epistemological that complement each other.
\end{abstract}

Keywords: Logical modalities; contingency, possibility; necessity.

A lógica da essência constitui no seu conjunto uma crítica da metafísica clássica, em particular a sua parte ontológica. A essência será a esfera da mediação e da reflexão do ser, da alteridade e da diferença. Através de suas três seções: a essência como reflexão nela mesma, o aparecimento e a efetividade, elabora-se o movimento dessa macroestrutura na microestrutura da categoria da efetividade. Kant apresentara na Crítica da Razão Pura as categorias modais numa tríade dual: possibilidade/impossibilidade; existência/não-existência; necessidade/contingência. Repercute em Kant e Hegel a tradição antiga, medieval e moderna das derivações escolásticoleibnizianas, segundo a qual o problema modal era elaborado, de um lado, na oposição lógico-ontológica, através da contradição possível/impossível, necessário/contingente, e, de outro, referindo-se ao problema metafísico da relação dínamis/enérgeia, potentia/ actus, essentia/ existentia (Cf. BAPTIST, 1992, p. 
99). Este é o problema que Hegel herda da tradição e face a ele elabora a sua teoria das modalidades.

\section{Estrutura Da Essência Das Modalidades ${ }^{1}$}

A teoria da modalidade hegeliana é tematizada no segundo capítulo da terceira seção da Lógica da Essência. Qual é, propriamente, o tema aqui explicitado por Hegel? Trata-se da lógica das modalidades em que a efetividade se determina nas assim chamadas modalidades: contingência, possibilidade e necessidade. As modalidades explicam a efetividade conforme sua determinação formal, real e absoluta. Nelas se reproduz a sequência lógica de graus do ser, da essência e da unidade de ambos como modos de determinação da efetividade por meio do entendimento filosófico (cf. LEIBNIZ, ARISTÓTELES/KANT, SCHELLING).

A análise lógica da essência da efetividade no segundo capítulo se desdobra em três itens (cf. HEGEL, 2014):

A) A efetividade, que é efetiva apenas conforme sua possibilidade formal, é necessidade formal ou contingência. Os dois polos da relação são, inicialmente, o efetivo e o possível. Eles são apenas diferenças formais, como ser posto contingente (cf. Hegel, $\ 35$ ).

B) A efetividade, que é efetiva na sua possibilidade real, é necessidade relativa. O efetivo e o possível determinam-se como efetividade real, isto é, como possibilidade real e necessidade relativa (cf. HEGEL, \36).

C) A efetividade, que é efetiva conforme sua determinação absoluta, é a necessidade absoluta. A necessidade relativa reflete-se e produz a necessidade absoluta, isto é, a possibilidade e a efetividade absolutas (cf. \37).

A lógica de Hegel das modalidades tem - como a lógica objetiva inteira - uma função crítica. Ela é a apresentação crítica da determinação lógicomodal da efetividade que é feita, habitualmente, pelo entendimento. Os modos de determinação apresentados criticamente da efetividade têm tanto um status ontológico como também um status epistemológico. Duas leituras são, portanto, possíveis: uma ontológica e uma epistemológica que se complementam reciprocamente.

\section{Leitura e Explicitação das Modalidades}

$\mathrm{Na}$ tradição filosófica a contingência era contraposta, normalmente, à necessidade, seguida de uma relação ao possível/impossível: Se é necessário, a negação é impossível e contraditória; se é contingente, a negação é possível e

${ }^{1}$ Este texto foi apresentado no VIII Congresso da Sociedade Hegel Brasileira, e foi publicado apenas um resumo restrito nos Cadernos de Resumos do referido evento. 
contraditória e não contraditória. Hegel refere-se, ao invés, ao problema da contingência, começando com a efetividade, possibilidade e necessidade, tomando o seu aspecto formal e esvaziada de todo conteúdo determinado. A ordem das categorias da modalidade enfatiza que a efetividade é o ponto fulcral da argumentação e o seu ponto de partida (cf. BAPTIST, 1992, p. 101).

\subsection{Determinação formal ou efetividade formal: Contingência}

No item " $A$ " explicita-se como tema central a crítica da possibilidade formal lógica. A explicação de um efetivo, no qual é apresentado sua mera possibilidade lógica, contém o déficit que se contenta, por um lado, com isto que ela não é impossível, o que não exige nada ulterior do que mostrar que ele não se contradiz a si mesmo. Mas esse critério conceitualizado aparentemente amplo não é nada, se visto mais de perto. Pois cada conteúdo contraditório se pode captar de forma que ele não se contradiga. A explicação de algo efetivo com sua possibilidade formal aponta, de um lado, a deficiência que a efetividade já contém sempre a possibilidade, - o que é efetivo, tem de ser, em todo caso, possível -, por outro lado, a possibilidade não é suficiente para fazer surgir a efetividade. Nem tudo o que é possível se torna também realidade. Esta é, pelo contrário, contingente. Toda possibilidade contém a indicação para seu oposto: "Possível" significa também "talvez não". A explicação da identidade essencial da Coisa por meio da sua possibilidade dissolve a própria Coisa. Ela pode ser ou também não ser. Ela não é necessária, mas contingente.

O item "A" elabora-se em três momentos: (1) A efetividade formal é apenas imediata, ou seja, não refletida. (2) Depois, a efetividade enquanto possibilidade reflete-se como identidade em si. (3) Enfim, a efetividade refletida é a unidade dela mesma e da possibilidade.

1) Efetividade formal: Hegel começa com a efetividade na sua imediatidade, que ainda não se reflete, pois trata-se de uma existência imediata, isto é, um ser em si dotado de interioridade e exterioridade. Este ser em si contém a possibilidade, pois tudo "o que é efetivo é possível" (HEGEL, \38).

2) Possibilidade formal: A efetividade como possibilidade reflete-se, ou seja, trata-se de um ser refletido em identidade consigo. A possibilidade tem dois momentos: o positivo como ser refletido em si mesmo e o negativo como algo deficiente que remete à efetividade e nela se completa (cf. \ 40).

$\mathrm{Na}$ possibilidade formal enquanto positiva é possível tudo o que não se contradiz, porém, o reino da possibilidade é o reino da multiplicidade ilimitada. Disto decorre uma diversidade indiferente, oposta e contraditória. Por isso, "tudo é, igualmente, um contraditório e, por conseguinte, impossivel" (id. \41). O ato formal de enunciar sobre algo que "ele é possível" é tão superficial e vazio como a proposição da contradição, afirma Hegel. Enunciar 
que A é possível é uma proposição de identidade formal (A = A). Porém, isso é algo meramente formal em que o conteúdo permanece idêntico consigo, algo possível. Falta aqui desenvolver o conteúdo, ou seja, fazer emergir a diferença nele.

De fato, o possível contém o negativo nele, pois a totalidade da forma não permanece apenas idêntica consigo, mas nega-se. "A possibilidade é, nela mesma também a contradição, ou ela é a impossibilidade" (id. \43). É possível enunciar A é A e igualmente, não A é não $\mathrm{A}$. Cada uma das proposições expressa a possibilidade de seu conteúdo. No A possível está contido igualmente o possível não A (cf. \44). Assim, o A contém o não A, uma contradição que se suprassume e se torna efetividade (cf. \ 45).

3) Necessidade formal: O efetivo é possível, isto é, a efetividade é posta como unidade dela mesma e da possibilidade (cf. \ 46). "Esta unidade da possibilidade e da efetividade é a contingência" (id. \48). O contingente é um efetivo determinado como possível. O contingente tem dois lados: De um lado, o contingente é a efetividade imediata, sem fundamento, assim como, o contingente é a possibilidade imediata, um efetivo sem fundamento. De outro lado, o contingente é o efetivo apenas possível como ser posto. Assim, o efetivo depende de um outro que é o seu fundamento: "O contingente não tem, portanto, nenhum fundamento porque é contingente; e igualmente ele tem um fundamento porque é contingente" (id. \51). O contingente é o movimento ("converter posto") não refletido entre efetividade e possibilidade sem fundamento em si: "Essa inquietude absoluta do devir dessas duas determinações é a contingência" (id. \53). Trata-se de um movimento em que cada uma das determinações converte-se imediatamente na oposta, então elas são idênticas neste movimento, constituindo-se isso na sua necessidade. Assim, o necessário é algo efetivo, porém, sem fundamento em si mesmo, pois tem sua efetividade através de um outro, isto é, no fundamento. "Assim a efetividade é idêntica consigo mesma naquilo que é diferente dela, a possibilidade. Enquanto esta identidade, ela é necessidade" (id. \54).

\begin{tabular}{|l|}
\hline Síntese $^{2}$ : \\
\hline 1 - "Efetividade formal, singularizada \\
\hline $\begin{array}{l}\text { - A efetividade como qualquer imediato, singularizado, "um ser ou existencia } \\
\text { em geral" (\$ 38). }\end{array}$ \\
\hline - Possibilidade formal, lógica \\
\hline $\begin{array}{l}\text { - A determinação fundamental da possibilidade formal, lógica é a } \\
\text { concebilidade destituída de contradição. Ela corresponde ao conceito de } \\
\text { possibilidade proposicional em Aristóteles: "possível que..." no sentido de } \\
\text { "não necessariamente, não assim" ou "pura e simplesmente possível" = }\end{array}$ \\
\hline
\end{tabular}

Esta síntese transcreve o Esquema da lógica hegeliana das modalidades proposto por Christian lber, 2015. 
"unilateralmente possível".

3 - Contingência, efetivo contingente/necessidade formal

- O efetivo contingente é, com efeito, ele mesmo necessário, contudo, ele tem sua necessidade em um outro que é ele mesmo um efetivo contingente. - O efetivo contingente é o possível no sentido de "não necessariamente, não assim" e "não necessariamente assim", portanto, o bilateralmente possível ou o contingente" (IBER, 2015).

O item " $A$ " argumenta acrescentando a cada determinação modal o aspecto da possibilidade. Assim, a primeira efetividade é apenas abstrata, como uma possível determinação. A possibilidade é ainda em si vazia, é possibilidade apenas possível. O seu manifestar-se um necessário/contingente é o imediato mudar um no outro. Por isso, a primeira efetividade possível é fundada nesse ser apenas possível. Este primeiro nível da efetividade apenas possível é a contingência que força toda determinação e, que o item seguinte elaborará como validade não simplesmente posta abstratamente, com implicações conceituais de efetividade, possibilidade e necessidade formais, mas como relação concreta (cf. BAPTIST, 1992, p. 111).

\subsection{Determinação real ou efetividade real: Necessidade}

O novo item apresenta-se como uma tentativa de solução das dificuldades do precedente. Aquela necessidade ainda posta em si como formal tinha um conteúdo qualquer que se podia expressar assim: "Tudo é possível"! Isto conduzia a concluir numa efetividade apenas possível, isto é, apena formal. Nesta vagueza podia-se compreender todo o múltiplo. De fato, este último dá-se, agora, como conteúdo determinado da efetividade real que resolve o argumentar, apenas, vazio e abstratamente possível, efetivo e necessário (Cf. BAPTIST, 1992, p. 111).

No item "B", o ponto fulcral é a crítica à lógica da possibilidade real (ontológica). A efetividade é aqui enérgeia (ação) que tem sua dynamis (força) em uma outra efetividade. A explicação de uma Coisa, isto é, a efetividade por meio da sua possibilidade real exige a presença de uma outra Coisa, que lhe é exterior e, portanto, entra em cena apenas como sua condição. Como singularizada a condição não pode fazer surgir a Coisa. A contradição da categoria da condição é que ela é algo autônomo contra a Coisa, mas, por outro lado, se dissolve por inteiro nela. Visto que a condição é sempre apenas um dos momentos múltiplos, nos quais a Coisa está, deve ser exigida a presença de outras condições. Apenas o âmbito completo das condições faz, de fato, surgir a Coisa. Ao mesmo tempo as coisas, que são acrescentadas como condições não têm como tais, nenhuma conexão entre si, elas são 
circunstâncias dispersas, de modo que não se sabe nunca, quando a sua enumeração é completa.

O item B estrutura-se também em três momentos:

1) Efetividade real - A necessidade resultante da necessidade formal tem um conteúdo diverso e múltiplo, por isso é uma efetividade real com muitas propriedades. Ela é a existência que se reflete e mantém a multiplicidade exterior no seu relacionar-se interior. Por isso "o que é efetivo pode agir; sua efetividade dá algo a conhecer através do que ele produz" (id. \57). O efetivo relaciona-se com outro efetivo, nisto manifesta seu aparecer, ou poder de agir como autônomo determinando-se face ao outro autônomo. A efetividade real tem a possibilidade nela mesma.

2) Possibilidade real - A possibilidade fazendo parte da efetividade real é uma possibilidade real plena de conteúdo. A possibilidade formal é uma identidade abstrata, apenas preocupada em não se contradizer. Porém, quando "alguém se envolve com as determinações, circunstâncias, condições de uma Coisa para conhecer a partir disso sua possibilidade, não permanece mais na possibilidade formal, mas considera sua possibilidade real" (id. S 59).

A possibilidade real é uma existência imediata que possui uma multiplicidade de circunstâncias que se relacionam com ela. A multiplicidade do ser aí é tanto a possibilidade quanto a efetividade, isto é, trata-se de uma efetividade real que enquanto refletida é uma possibilidade real. Esta é a totalidade da forma posta, constituindo o todo de condições que se determina, que determina o outro e retorna em si (cf. $\$$ 61).

O possível enquanto é uma identidade formal, não deve se contradizer. Porém, o possível é uma conexão múltipla de diversidade e oposição, portanto é algo contraditório. Por isso, $\mathrm{H}$ afirma que se deve mostrar e descobrir a sua contradição. Esta contradição não é apenas algo comparativo, mas o possível tem nele mesmo a contradição e todas as condições estão presentes nele. "Quando todas as condições de uma Coisa estão completamente presentes, então ela entra em efetividade; - a completude das condições é a totalidade a respeito do conteúdo, e a Coisa mesma é esse conteúdo determinado a ser tanto um efetivo como um possível" (id. \62). As condições fazem parte do conteúdo do possível, não é algo que está fora dele, "aqui, ao contrário, a efetividade imediata não é determinada a ser condição por uma reflexão que pressupõe, mas está posto que ela mesma seja a possibilidade" (id. \62).

A possibilidade real pode ser efetividade ou possibilidade: 1) Como efetividade que aparece imediata e autônoma torna-se um ser refletido e momento de um outro; 2) Como possibilidade de um outro suprassume-se e passa a ser efetividade. São momentos idênticos que coincidem consigo mesmo e a possibilidade real é ela própria efetividade (cf. $\$ 63$ ).

3) Necessidade real - A negação da possibilidade real e o suprassumir dela é a necessidade real (cf. \64). Hegel afirma que o necessário não pode ser 
de outro modo, porém, o possível pode ser de outro modo, pois ele é o ser posto que pode ser outro. A possibilidade formal passa para o outro, porém, a possibilidade real por ter a efetividade em si, ela já é a necessidade real. Aqui, trata-se da possibilidade real que não pode ser de outro modo, isto é, "sob essas condições e circunstâncias não pode suceder algo outro; assim, "a necessidade real é, relação plena de conteúdo" (id. \65).

A necessidade real é, porém, relativa, pois ela tem como ponto de partida a contingência. O efetivo real é um ser determinado envolto por uma multiplicidade de circunstâncias. Então, o ser imediato tem em si a possibilidade real, sendo esta, então, a unidade da possibilidade e da efetividade. Porém, a possibilidade real enquanto unidade do possível e do efetivo, ainda não é refletida, isto é, não há o movimento que retorna a si da necessidade real (cf. \66). A necessidade real é relativa, isto é, depende da contingência, pois tem um conteúdo indiferente frente à forma. Assim, a necessidade real é uma efetividade limitada, ou seja, contingente (cf. \67). Há uma diferença entre a forma da necessidade real e o seu conteúdo, pois este é ainda contingente. A necessidade real mostrou-se como possibilidade real posta, enquanto o ser outro da efetividade, que contem, portanto, a contingência. A necessidade real é incapaz de retornar a si a partir daquele ser outro inquieto da efetividade e da possibilidade, isto é, ela não retorna a si a partir de si mesma (cf. $\int$ 68). Porém, em si, ainda não desenvolvida, está presente a unidade da necessidade e da contingência, ou seja, a efetividade absoluta (cf. \69).

\begin{tabular}{|c|}
\hline Síntese: \\
\hline 1 - "Efetividade real \\
\hline 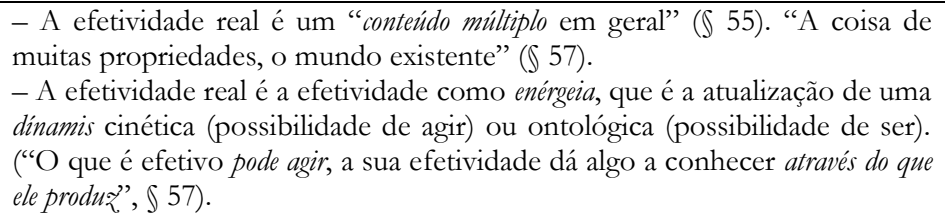 \\
\hline 2-Possibilidade real \\
\hline $\begin{array}{l}\text { - Ela forma um círculo de determinações, circunstâncias e condições de } \\
\text { uma Coisa real que lhe são exteriores. } \\
\text { - A conexão real da condição se apresenta como processo da possibilidade } \\
\text { real que se suprassume, por meio do qual a efetividade real é produzida. } \\
\text { - Apenas o âmbito completo das condições faz surgir a efetividade real. }\end{array}$ \\
\hline 3 - Necessidade real \\
\hline $\begin{array}{l}\text { - A necessidade real é a necessidade relativa ou exterior no sentido do ser } \\
\text { produzido por meio de condições que são exteriores à própria Coisa real. } \\
\text { - O ponto de partida e o resultado da necessidade real é apenas uma Coisa } \\
\text { real contingente" (IBER, 2015). }\end{array}$ \\
\hline
\end{tabular}


A efetividade real mostrou dois novos conceitos: o real e o outro, ou seja, a realidade e a alteridade. Estes dois conceitos se interconectam um no outro: a necessidade é contingente no seu ser concretamente real e no seu compreender em si, seja tanto sua própria possibilidade como tal (poderia ser de outro modo, mas é assim) como a possibilidade do outro (no seu contexto de ser também outra efetividade possível). Uma vez que esta necessidade real e concreta é relativa, então aponta o conteúdo efetivo de algo qualquer determinado, agora sua contingência tem um sinal positivo. Porém, isto já constitui a transição à determinação absoluta, em que não se trata mais de um jogo formal ou real de conteúdo que se duplica na inquietude da alteridade interna, mas da efetividade absoluta (cf. BAPTIST, 1992, p. 118).

\subsection{Determinação absoluta}

A efetividade absoluta constitui o novo elemento como ponto de partida da argumentação hegeliana. A efetividade absoluta não é meramente a enérgeia da efetividade real, mas a enteléquia agente, isto é, a totalidade plena que se manifesta na determinação como algo autossuficiente.

No item "C", a questão central é a crítica à determinação absoluta da efetividade, quer dizer, na sua necessidade absoluta. Na necessidade absoluta a necessidade e a contingência coincidem imediatamente.

A determinação absoluta volta-se contra a figura da reflexão-em-outro que era dominante na necessidade real. O que torna necessária a efetividade de uma coisa, não pode conter essa apenas como possibilidade, mas precisa antecipá-la completamente, portanto, ser essa própria Coisa. $\mathrm{O}$ recurso às determinações exteriores à coisa na necessidade real se afasta do pensamento da autodeterminação (vazia): a Coisa é, porque ela é. A dificuldade das categorias que tratamos, necessidade real e absoluta, é a seguinte: Explicar uma Coisa por meio de uma outra, é uma contradição, explicá-la por meio de si mesma, é tautológico. A explicação de uma Coisa por meio de uma relação a uma outra, ou a si mesma, é um formalismo, isto é, um modo de explicação formal. Tais explicações defeituosas são objeto da crítica na lógica da essência.

A coincidência imediata da necessidade e do acaso no conceito da necessidade absoluta caracteriza em geral a necessidade na natureza. A efetivação de uma regularidade necessária na natureza é a obra do acaso, (isto é), enquanto a natureza permanece à deriva. A necessidade da natureza é a necessidade do contingente. Dentro da natureza predomina, portanto, o acaso. A necessidade das leis nas configurações da natureza se realiza apenas, nessa medida, como as constelações contingentes dessas configurações a condicionam. Assim a progressão necessária na evolução está mediada por meio dos acontecimentos casuais da mutação. Se não quiser se limitar às leis casualmente realizadas, a subjetividade cognoscente tem que superar essa 
contradição contida na natureza que Hegel esclarece aqui no fim da lógica da essência.

Saber significa para Hegel conhecer a necessidade interior de uma Coisa. A lógica da essência permanece insuficiente, na medida em que ela apenas visa conhecer a Coisa como mediada, ou seja, como determinada por meio de outra Coisa. Põe-se a questão: Por que conceituar deste modo? A resposta é apenas uma necessidade relativa. A Coisa é relacionada a um fundamento que reside em alguma outra Coisa. Na lógica da essência há apenas uma alternativa para a explicação da Coisa por meio da reflexão em outro, isso é a explicação da Coisa na relação apenas consigo mesma. A lógica do conceito supera essa alternativa entre reflexão em outro e reflexão em si, entre contradição e tautologia.

A explicação efetiva de uma Coisa conceitualiza sua necessidade como mediada, isto é, não apenas formal e não por meio de uma outra Coisa, mas por meio de si mesma. Aqui a reflexão em outro e a reflexão em si se encontram em uma unidade, de modo que a alternativa entre contradição e tautologia está superada. Para a explicação efetiva de uma Coisa é necessário a alegação de um fundamento que a coisa de fato contém em si. Com a alegação do fundamento interior, a identidade essencial de uma Coisa não é mais posta em relação a sua efetividade múltipla do aparecimento. O fundamento já contém, pelo contrário, a Coisa como um todo. Com essa transição do conhecer coincide a questão por que com a questão o quê, ou seja, a explicação efetiva da coisa ocorre, portanto, na lógica do conceito. Vejamos a reconstituição do texto sobre a necessidade absoluta:

a) Efetividade absoluta: A necessidade formal ainda não tem conteúdo, porém, a necessidade real já é determinada, porque ela tem "nela sua negação, a contingência" (\$ 70). Então, a necessidade determinada é imediatamente necessidade efetiva, ou seja, efetividade absoluta, "porque seu ser em si não é a possibilidade, mas a própria necessidade" (\$ 71$)$.

b) Necessidade absoluta: Esta efetividade absoluta é uma determinação vazia, ou seja, contingência, porque ela é a unidade de si e da possibilidade. A determinação vazia da efetividade faz dela uma mera possibilidade, pois pode ser de um modo ou de outro. A possibilidade é absoluta, pois, tanto pode ser determinada como possibilidade quanto como efetividade. Então, a efetividade absoluta em sendo esta indiferença é posta como determinação vazia, isto é, contingente (cf. $\int 72$ ).

Hegel recapitula o movimento da necessidade real incorporando nela a contingência. A necessidade real contém os momentos da efetividade e da possibilidade como unidade positiva mudando de um lado para outro e nisso põe-se como negativo nos dois momentos da necessidade real. A necessidade suprassume-se e põe-se como contingência repelindo-se e retornando a si mesma (cf. $\left.\iint 73-74\right)$. 
A forma permeou todas as suas diferenças, isto é, atravessou o ser e a essência, tornando-se idêntica ao conteúdo. Então, há a unidade de forma e conteúdo, ou seja, de possibilidade e efetividade, sendo necessidade absoluta (cf. $\left.\int 75\right)$.

c) As determinações da necessidade absoluta: A necessidade absoluta é a verdade, pois os dois momentos - efetividade e possibilidade - retornaram para si, bem como a necessidade formal e real. A necessidade absoluta é ser e essência tendo em si o fundamento e a sua condição: Ela é, então, porque ela é"(cf. \ 76). Ela é negatividade absoluta, sendo efetividade diferenciada na figura de momentos opostos e autônomos. Efetividade e possibilidade tornam-se efetividades livres sem relação com o outro, cada um é nele mesmo o necessário. O contato entre elas é uma exterioridade vazia, isto é, "a efetividade de um no outro é a somente-possibilidade, a contingência” (\ 77). Essa contingência é a necessidade absoluta nas efetividades livres. Estas efetividades, afirma Hegel, são "apenas fundadas em si, configuradas para si, manifestam-se apenas a si mesmas" (id. \ 78). Elas são simples e possuem a negatividade absoluta, a contradição que as torna livres no seu ser. Elas configuram-se de forma diferente umas frente às outras com um conteúdo determinado necessário, que os seres no seu devir ou passar do ser para o nada perecem. Assim, os seres aparecem e se refletem, ou seja, trata-se do devir refletindo-se e aparecendo na exterioridade, mantendo, ao mesmo tempo, a sua interioridade como uma relação de identidade. Em outras palavras, é o passar do efetivo (ato, enérgeia) ao possível (potencialidade, dínamis), do ser ao nada, coincidindo consigo mesmo. Esta é a contingência dos seres como uma necessidade absoluta (cf. \ 78).

Estes são os modos da identidade do ser negando-se a si mesmo como necessidade formal, depois real e, enfim, absoluta. A efetividade refletese nestes modos do ser tornando-se substância, isto é, uma unidade refletindose, relacionando-se e produzindo contingência. Assim, o movimento cego da necessidade é a própria exposição do absoluto que se move exteriorizando-se e mostrando-se no próprio movimento de si mesmo (cf. \ 79).

\begin{tabular}{|l|}
\hline Síntese: \\
\hline $\mathbf{1}$ - "Efetividade absoluta \\
\hline - Ela subsiste carregando a si mesma, fundamentada e condicionada em si \\
por meio de si mesma, não tem mais a possibilidade real do seu subsistir em \\
um outro efetivo que a viabiliza, mas em si mesma. A Coisa "é, portanto, \\
porque ela é" ( $(\mathbb{7 6})$. \\
\hline $\mathbf{2 - N e c e s s i d a d e ~ a b s o l u t a ~}$ \\
\hline - A contingência, que a necessidade real tinha por pressuposição, se mostra \\
como seu pôr próprio ou produto. A necessidade real, que se determina a \\
partir de si mesma para a contingência, é a necessidade absoluta. \\
- A necessidade absoluta é a unidade da essência e do ser na forma do ser. \\
\hline
\end{tabular}




\section{3- As determinações da necessidade absoluta \\ - Os lados da relação da necessidade absoluta são figuras/configurações autossuficientes ("efetividades livres", \ 77) que têm elas mesmas o caráter do necessário. \\ - Ao ser firme e endurecido dessas figuras/configurações não se vê sua relação necessária essencial uma para com a outra. Esta se realiza, portanto, apenas em um "contato" (\$ 77) contingente o que é equivalente à negação do seu subsistir. "Cega” (\$ 77) é a necessidade absoluta, porque ela se impõe apenas através do acaso.}

$\mathrm{Na}$ necessidade absoluta a necessidade e o acaso coincidem imediatamente. A contingência é a necessidade absoluta e a necessidade absoluta é a contingência. Na efetividade absoluta a destruição das suas figuras autônomas se une de modo descontrolado com o seu emergir. Hegel fala do "reveter absoluto de sua efetividade na sua possibilidade, e de sua possibilidade na efetividade" (\$ 77). A cegueira da necessidade absoluta e a contingência absoluta são correspondentes e produzem os resultados aporéticos do capítulo sobre a efetividade.

A relação da necessidade absoluta, a unidade da necessidade e da contingência, que marca a unidade aqui alcançada da essência e do ser, é reconduzida por Hegel ao conceito de substância absoluta que se explicita ou se manifesta nos seus acidentes. $\mathrm{Na}$ "alternância dos acidentes" da substância se reproduz aquele reverter absoluto das figuras da efetividade absoluta, mas agora compreendida na substância absoluta. Ela é a base, na qual a relação da necessidade absoluta se transforma para a liberdade e a transparência do conceito" (IBER, 2015). Os modos de determinação lógico-modais da efetividade mostram esta como ela existe na natureza, portanto, como uma efetividade que ainda não é permeada da liberdade do espírito.

\section{Diálogo Merkel E Obama A Partir das Categorias Modais Hegelianas $^{3}$}

Diálogo entre Angela Merkel e Barak Obama na Cúpula do Clima do G 7 no Castelo de Elmau na Bavária, Alemanha, dia 08/06/2015, sobre a proteção do clima em categorias modais:

Angela Merkel: Que dia lindo e que paisagem magnífica desta região da Bavária. Como tu estás, Obama?

${ }^{3}$ Este diálogo foi publicado originalmente em Opinião Filosófica - $h$ ttp://abavaresco.com.br/wp/?paged=2. Porém, ele foi completamente ampliado e reformulado para este artigo. 
Barak Obama: Estou aos trancos e barrancos, porque tinha que resolver uma grande crise econômica no meu país.

Angela Merkel: Deixa de lado as tuas preocupações! Agora estamos em uma das regiões mais ricas do mundo. Viva Bavária, viva! Que bom que eu te achei por aqui sozinho nesse banco, Obama, porque quero falar cara a cara contigo sobre a proteção do clima.

Barak Obama: Pode falar.

Angela Merkel: Eu afirmo que a proteção do clima é uma coisa boa. Por sinal, tu sabes que isso é um juízo valorativo que, segundo Hegel, pertence ao grupo dos juízos do conceito que são juízos normativos?

Barak Obama: Já ouvi falar do Hegel. Ele é um velho filósofo continental, mas especulativo demais. Para nós, nos Estados Unidos, nas universidades nós ensinamos somente três coisas distintas: pragmatismo, utilitarismo e filosofia analítica da linguagem. Para nós isso é o suficiente, porque útil.

Mas a tua afirmação é somente um juízo assertórico, falta ainda uma fundamentação. Tu podes fundamentar a tua afirmação acerca da proteção do clima?

Angela Merkel: Sim, mas então temos diante de nós não mais o juízo assertórico, mas o juízo apodítico. Isso é para Hegel o juízo normativo fundamentado. Entendeu?

Barak Obama: Para mim tudo isso é muito complicado, complicado demais. Esses alemães sempre pensam que bebem a sabedoria direto da fonte. Então, tu podes fundamentar a tua afirmação?

Angela Merkel: Sim, claro. Olha só! A fundamentação da minha afirmação reza: a proteção do clima é uma coisa boa, porque ela é simplesmente possível. Como Hegel diria: "Em geral, costuma-se dizer da possibilidade que consiste apenas na "pensabilidade"” (HEGEL. Enc. \143 Adendo).

A Angela Merkel representa a possibilidade formal, lógica: tudo aquilo que não se contradiz é possível. A Senhora Angela Merkel defende a categoria da possibilidade formal. Por quê?

Angela Merkel: Eu gosto muito da categoria da possibilidade formal porque ela facilita nossa vida inteira. Mas ah! Heim? Obama, não é assim? 
Ela se refere ao Hegel na Enc. $\int 143$ Adendo:

É possível que hoje de tarde a lua caia sobre a terra, pois a lua é um corpo separado da terra e por isso pode cair tão bem quanto uma pedra que foi lançada para o ar. É possível que o Sultão se torne Papa, pois é um ser humano e pode, enquanto tal, converter-se ao cristianismo, tornar-se um sacerdote católico etc.

Angela Merkel: Isso não é uma maravilha? O mesmo pode ocorrer com a proteção do clima. O desprezo, que nós atribuímos à proteção do clima, pode se reverter de repente na própria proteção do clima. Isto é simplesmente possível. Isso não é fantástico, Obama?

Barak Obama: Olha Angela, isso não é demasiado fácil? Tu não sabes que a possibilidade formal não serve para fazer surgir a efetividade? Nem tudo o que é possível se torna também realidade. Ao contrário, cada possibilidade formal contém a indicação para seu oposto. O que só é possível, também é impossível. O que apenas é possível, não é necessário, mas contingente.

Eu acho melhor que a gente defenda a categoria da possibilidade real. Eu sou um pragmático e um realista: "Quando estão presentes todas as condições, a Coisa deve tornar-se efetiva" (HEGEL. Enc. \147).

Mas como tu sabes, é muito raro que todas as condições estejam presentes, e isso vale sobretudo para a questão da proteção do clima. Acredito, portanto, que a proteção do clima nunca vai se tornar uma necessidade real, ainda menos uma necessidade absoluta. Tenho minhas experiências acerca desse fato. Eu mesmo sou uma má condição para a proteção do clima. Entendeu, Angela?

Angela Merkel: Agora entendi. Mas isso não é muito agradável. Que barbaridade! Em todo caso a proteção do clima não pode ter o caráter de uma efetividade absoluta que contém sua possibilidade real não mais fora dela, mas em si mesma e é, por isso, em si necessária, portanto, algo que não pode mais ser de outro modo.

Barak Obama: Posso concordar completamente com a tua constatação, sem tirar nem pôr.

Angela Merkel: $O$ único que tem o caráter de uma necessidade absoluta é nosso interesse nacional egoísta. Isso significa, segundo Hegel, o seguinte: a Coisa é, por que ela é. A justificativa dos nossos interesses nacionais egoístas é uma fundamentação tautológica, portanto, uma fundamentação que é ao mesmo tempo uma não fundamentação. A 
fundamentação deve ser, portanto, dispensada e suprassumida sem contradição. Nisso, na necessidade absoluta, a necessidade e o acaso coincidem imediatamente. Daqui resulta - como já Hegel sabia - que nas relações internacionais não domina o estado civil, mas o estado natural (cf. HEGEL. Filosofia do Direito \333). A necessidade absoluta de nossos interesses nacionais egoístas se impõe internacionalmente através do acaso e com violência.

Mas isso não é uma realidade mais triste, Obama?

Barak Obama: Sim, tudo isso o que tu disseste é a plena verdade. Pior. A nossa necessidade absoluta é ao mesmo tempo a nossa contingência absoluta. Aqui falta infelizmente a racionalidade, mas no estado natural não temos uma outra saída. Veja só a China! E o Putin da Rússia não é melhor.

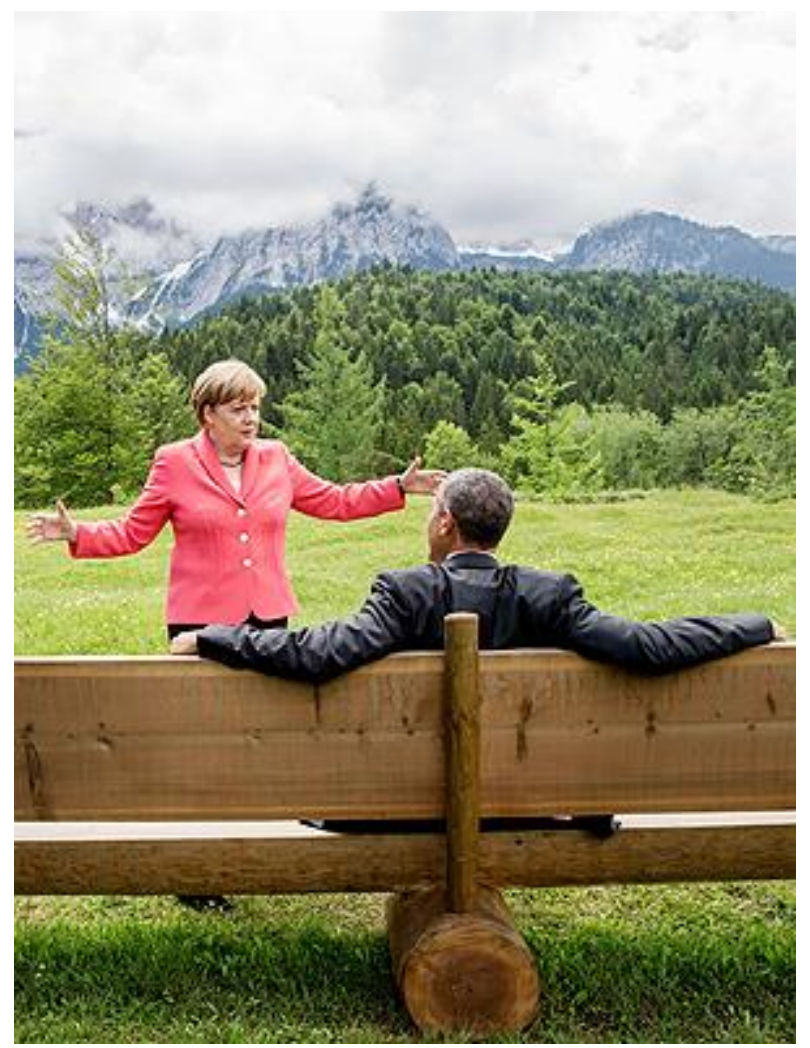




\section{Referências}

BAPTIST, Gabriella. Il problema dela modalità nelle logische di Hegel. Um itinerário trailpossibile e ilnecessario. Genova: Pantograf, 1992.

HEGEL, G. W. F. A Efetividade. In: HEGEL, G. W. F. Wissenschaft der Logik - II. Frankfurt amMain: Suhrkamp, 1986, v. 6. Tradução de Michela Bordignon, Agemir Bavaresco, Christian Iber, Marloren Miranda e Tomás F. Menk. Revisão Técnica: Luis Sander, 2014. Impresso usado em Seminário 2014 Pós-Graduação Filosofia PUCRS.

IBER, Christian. Esquema da lógica hegeliana das modalidades. Porto Alegre, 2015. Impresso.

Email: abavaresco@pucrs.br

Recebido: $10 / 2016$

Aprovado: 12/2016 